
Paper 69
CCivil-Comp Press, 2014
Proceedings of the Second International Conference on
Railway Technology: Research, Development and
Maintenance, J. Pombo, (Editor)
Civil-Comp Press, Stirlingshire, Scotland.

\title{
Monitoring of Railway Viaducts and Bridges
}

\author{
H. De Backer, A. Outtier, K. Schotte, W. Nagy and P. Van Bogaert \\ Department of Civil Engineering \\ Ghent University, Belgium
}

\begin{abstract}
Monitoring of structural parameters during construction can be an important aid during execution. Especially when studying the long-term behaviour of structures, e.g. build-up of ground pressures or fatigue effects, it can become necessary to resort to monitoring. This research paper discusses two such projects: the "Iris" railway viaduct and the Pede viaduct, both near Brussels, Belgium.

This article gives an overview of these experiences and on the lessons learned and structural consequences. When looking at the long-term behaviour of a structure, both temperature changes and strains are important values to register. It seems as if the daily variations of the temperature have an important influence on the structure, even more so than the strain variations measured during static load tests. A conclusion could be that daily temperature variations cannot be neglected in the design although often regarded as a minor load, especially for railway structures where joints are often located further apart. Although this paper reflects the structural assessment of two projects in particular, these techniques are applicable for several other structures and therefore contribute to an improved understanding of both existing structures as well as future design possibilities.
\end{abstract}

Keywords: railway viaduct, strain, accelerometer, monitoring, structural assessment, steel box, long-term temperature effects.

\section{Introduction}

Assessment of structural elements in civil structures through monitoring techniques is often necessary to verify certain design hypotheses or to evaluate the condition of existing structures. Therefore, both short-and long-term behaviour monitoring of structural parameters often imposes itself. Possible structural parameters to be verified are strains, temperatures, accelerations, frequencies, etc. The Iris railway viaduct in Belgium is such an example where a short-and a long-term monitoring for 
strains and accelerations was setup, Van Bogaert and De Pauw [1]. This viaduct is part of the Diabolo project, which was created to expand the existing possible approaches to the end station for railway connections to the Brussels Airport in Belgium. To do this, several civil structures were needed, and one of the largest is the "Iris" railway viaduct in Haren, Brussels. This viaduct has a total length of approximately $800 \mathrm{~m}$ and contains 35 spans carrying two railway tracks. Because of its rather unusual design, several structural assessments were needed. The structural assessment set out in this paper reflects also the possible monitoring techniques for other civil structures, newly built as well as existing, De Backer et alii [2].

The second example deals with the Pede viaduct, [3]. As part of a large-scale project in order to improve the accessibility of the Belgian capital by train, the existing railway line between Brussels and Ghent is expanded from 2 to 4 tracks over a length of $25 \mathrm{~km}$. This line crosses the valley of the river Pede by a $523 \mathrm{~m}$ long historic viaduct, built in the $1930^{\text {"e }} \mathrm{s}$. In those days the viaduct was chosen over large backfills in the valley due to poor soil conditions. The structure consists of 16 three-hinged reinforced concrete arches with a span of $32 \mathrm{~m}$ and a maximum height of $20 \mathrm{~m}$. Four arches form an independent group, as they are separated from the rest of the viaduct by double pier structures, allowing for compensation of the thrust force of each group. In Figure 1 a front view of the concrete structure is shown. The viaduct is a benchmark in the rural environment through its dominance midst the gentle slopes of the Pede valley. Extension of the railway facilities to 4 tracks needs to widen the existing structure by two additional lateral viaducts, with respect for the heritage structure. Therefore the arch structure and the existing piers should be left apparent as much as possible. The arches should keep their function and continue to behave as a four-span group. Important guidelines in making the new design were the contrast of old and new technology, keeping the four-span static behaviour with the repetition of $32 \mathrm{~m}$ spans and leaving the characteristic view of the hollow piers.

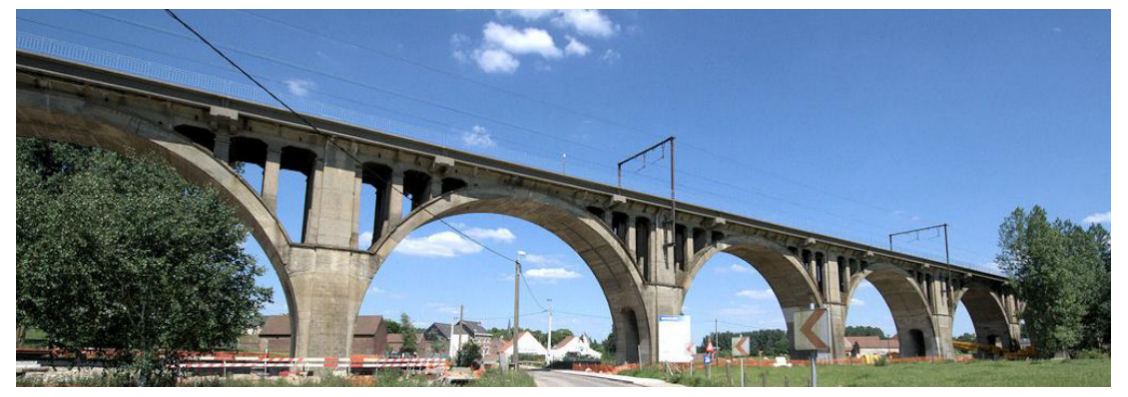

Figure 1: Front view of the historic Pede viaduct.

\section{The "Iris" viaduct}

\subsection{Design of the Iris piers}

The area in which the viaduct is built, is designated as a future residential living area. Therefore, the Brussels' city authorities asked for a particular and attractive structure, showing efforts for form finding and elegance. This was inspired by the 
fact that the piers of this viaduct reach a maximum height exceeding $18 \mathrm{~m}$, which is unusual in a rather flat countryside as the central part of Belgium. The piers consist of a vertical shaft supporting a system of curved branches, connected by a horizontal concrete slab. The shape of the piers reflects that of the iris flower, which is the symbol of the Brussels-Capital Region. Part of the "Iris" viaduct is shown in Figure 2.

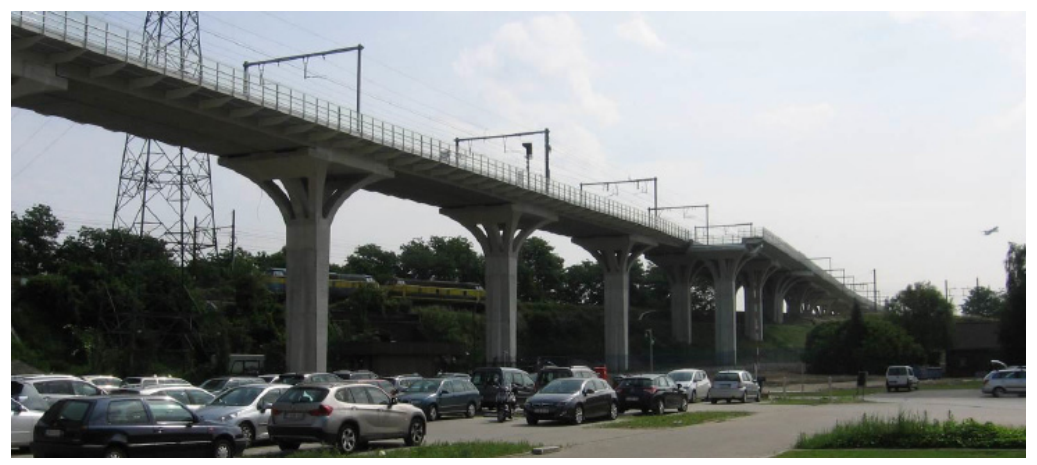

Figure 2: Part of the Iris viaduct in Haren, Brussels.

Two different types of piers are used in the viaduct depending on the number of supported tracks. For the entire viaduct, 28 double track piers were constructed with six curved branches, while six single track piers were constructed with four curved branches, as shown in Figure 3. The piers themselves have a cross-shaped base and a rectangular head. Because of the variation of the ground level, the height of the piers varies from $6,0 \mathrm{~m}$ to $14,8 \mathrm{~m}$ resulting in a different body shape for every single pier. Only the pier heads have a constant height of $4,8 \mathrm{~m}$. Because of the complexity of the pier heads, the curved branches were prefabricated.

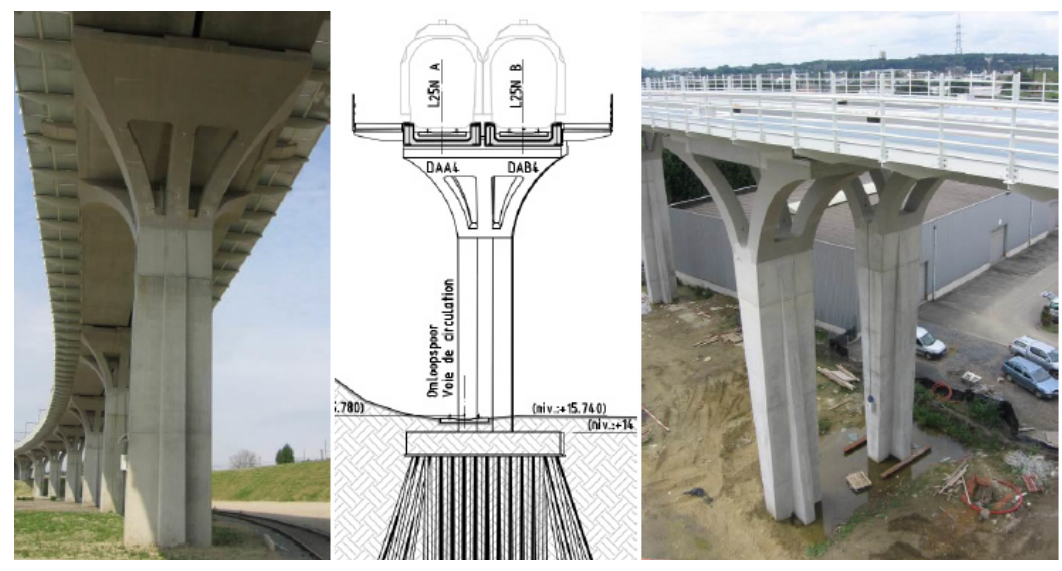

Figure 3: Double track pier (left), foundation of a double track pier (middle), single track pier (right).

The lower part of the piers was cast on site using heavy formwork. The connection node of the curved parts and the vertical shaft was also cast in situ. Further on, a top slab between the curved branches was cast to connect the curved members. Finally the piers were connected with U-shaped precast and prestressed members to support the ballast and the rail tracks the whole Iris railway viaduct is 
also situated in an area with very poor soil characteristics. Therefore, numerous micropiles and screw piles were needed to support the structure.

Due to the height of the piers, braking and acceleration forces introducing horizontal displacements become significant. Also because of the longitudinal double curved shape of the viaduct, centrifugal forces increase the resulting deformations of the piers. Besides the resulting forces and stresses, the deformations become an important design criterion. For the design of the piers, a comparison was made between stiff and flexible piers. The difference is in the fact that stiff piers have a high resistance to the deformations but have a poor distribution for the acting forces divided among several piers. While flexible piers have a larger deformation but there is also an improved distribution of the acting forces over several piers. Therefore, a structural assessment of the structure for both short-and long-term behaviour imposes itself.

\subsection{The monitoring programme}

\subsubsection{Short-term monitoring}

As previously mentioned, a short-and long-term monitoring programme was setup for the Iris railway viaduct to verify the design and behaviour of the structure. For the short-term monitoring a one day load test with two freight trains was set. Therefore, 54 strain gauge measuring points were installed on a double track pier (pier PA8) and 38 on a single track pier (pier PC10).All of these measuring points were of the type half-bridge strain gauges eliminating both Poisson and temperature effects. Especially in case of long-term monitoring, half-bridge strain gauges give a more accurate signal. Based on the experience on several other projects, an accuracy of one microstrain $(\mu \mathrm{S})$ could be achieved.

The measuring points were mainly located on the branches of the piers as shown in Figure 4. On every branch eight strain gauges were installed, four equally divided over the lower circumference and four over the top circumference. In addition, four equally divided strain gauges were installed on the pier itself, just below the connection of the pier with the branches. Finally, two strain gauges were installed between a couple of branches to measure the splitting forces. For the double track pier PA8, a strain gauge was placed between the two middle branches and one between two arbitrary chosen outer branches. In contrast, for the single track pier PC10, both outer branches were monitored because there are no middle branches.

In addition, six strain gauge measuring points were attached to the rail tracks itself as shown in Figure 5. Therefore, dynamic strain measurements could be registered to evaluate the distribution of the braking and acceleration forces. These strains were measured with a frequency of $10 \mathrm{~Hz}$ and an accuracy of one microstrain. To minimize the effects of electromagnetic noise in the recorded data, grounded shield cables were used. 


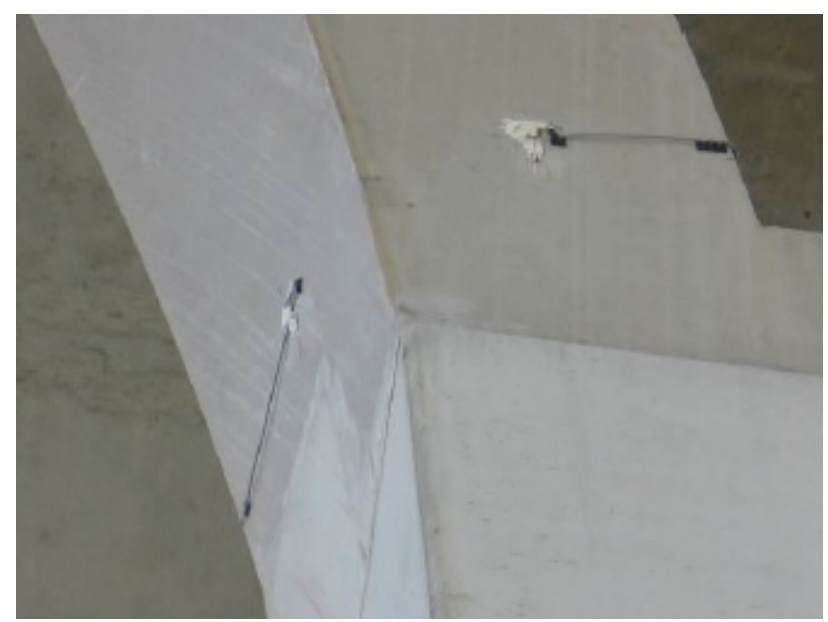

Figure 4: Installed strain gauges on a branch.

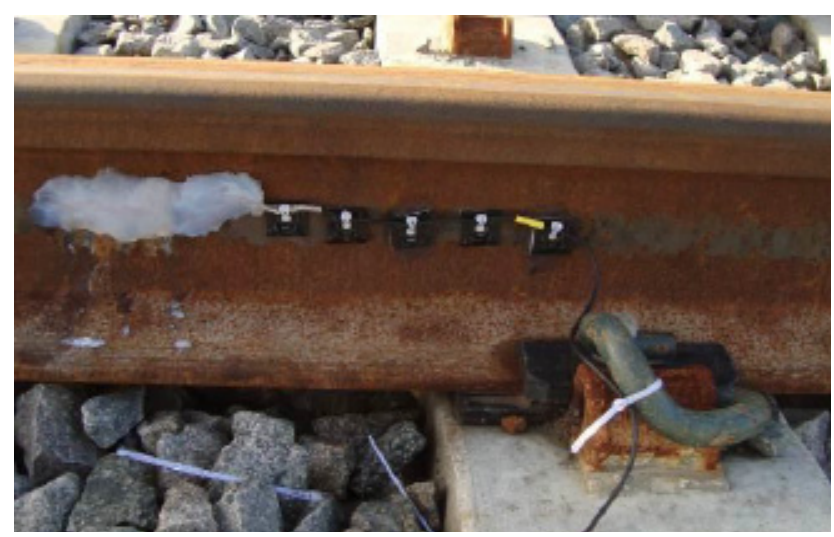

Figure 5: Strain gauge on a rail track.

Also several acceleration measurements were carried out using uniaxial highprecision accelerometers. These were attached on four different locations of each measuring pier. Two accelerometers were fixed on a concrete branch to measure both transverse and longitudinal vibrations. The other two accelerometers were fixed on the pier just below the head of the pier. Just as for the branch, the accelerometers measure both transversal and longitudinal vibrations. The measurements were registered using a sample rate of $200 \mathrm{~Hz}$. In addition, the data not only reflect the influence of a freight train on the structure but also indicates the influence of ambient parameters such as wind on the structure.

For the short-term monitoring programme, two freight trains, shown in Figure 6, were used for both static and dynamic measurements. The first freight train consisted of two locomotives of 110 ton each and five carriages of approximately 78 ton. The second train only consisted of two locomotives of 110 ton. With these trains, several static and dynamic measurements were carried out. For the static ones, four different symmetric and asymmetric positions were taken. Therefore, the most disadvantageous position and the resulting maximum stresses could be determined. Concerning the dynamic measurements, several braking tests with different speeds were performed. 


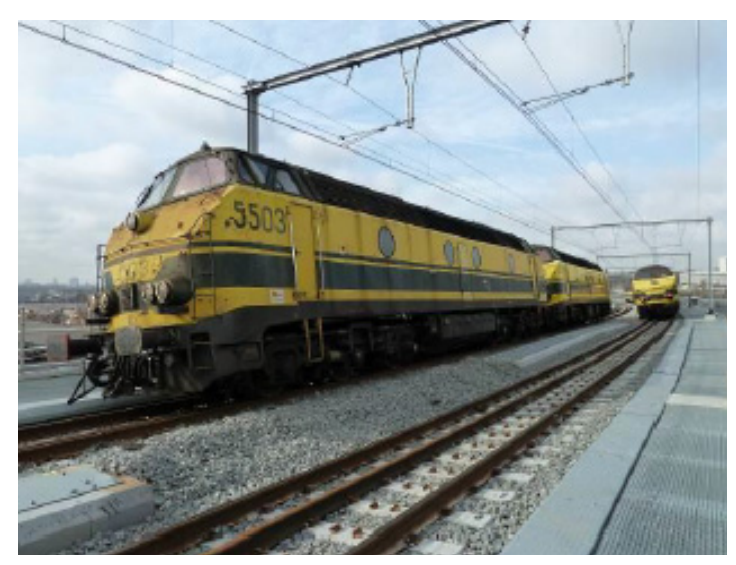

Figure 6: Two freight trains used for the load tests.

The main reason for these tests is to verify the stiffness of the piers through the distribution of the resulting braking forces in the rail tracks to different piers. In addition, strains were monitored during these braking tests. Also acceleration measurements were carried out during the static and dynamic measurements. Even between the freight train passages, acceleration measurements were registered to verify the influence of ambient vibration to the structure.

\subsubsection{Long-term monitoring}

When studying the long-term behaviour of the structure, it is necessary to monitor certain structural parameters. In the case of the Iris viaduct, the installed strain gauges of piers PA8 en PC10 were monitored during one year using an autonomous measurement system as shown in Figure 7. The advantage of using such a system is its independence, which is necessary in such a terrain. The strains of all strain gauges are automatically stored every minute on a data logger. To ensure the independence of the data logger, measures had to be taken to solve the power problems. As often the case for field measurements, no power supplies are available during a long-term monitoring programme. Therefore, a solar panel was installed to enlarge the battery life. Also a GSM-module was installed to download and verify the data directly in the office resulting in minimal maintenance.

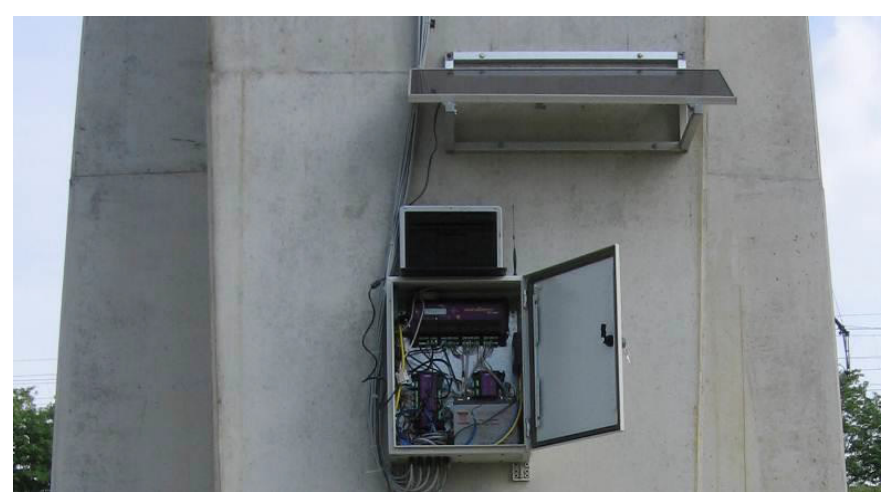

Figure 7: Autonomous measurement system. 


\subsection{Results}

\subsubsection{Static strain measurement during the load test programme}

During the one day testing programme, strains were measured of the 54 strain gauges on pier PA8 and the 38 strain gauges on pier PC10. Figure 8 illustrates the measurements of two branches of pier PA8. More particularly an outer and a middle branch were chosen (left (and middle) branches on Figure 3, left; strain gauge 3 (101) up to 6 (104) and 7 (105) up to 10 (107): upper and lower part of the outer (middle) branch). The different train positions during the static strain measurements are visible. Only the second train position reflects a symmetric position where the freight trains are equally divided over the pier. All the other positions are asymmetric ones.

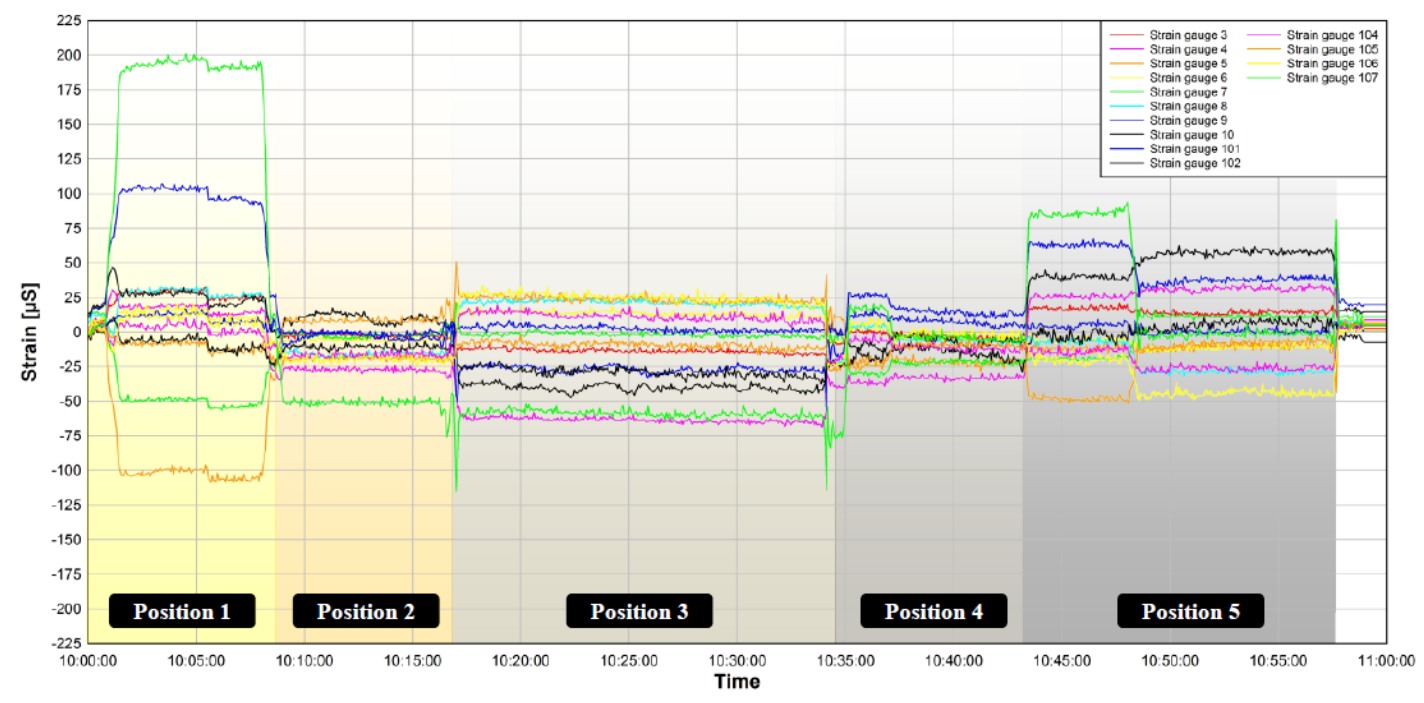

Figure 8: Strain of two branches of pier PA8 during static strain measurements.

It can be noticed that the asymmetric positions are the dominant ones for the resulting strains and therefore the stresses. Especially position 1 where both trains are positioned left of the middle of pier PA8. Therefore, the left branches of the pier (branches 4, 5 and 6) are directly loaded. Figure 9 illustrates the strains in all the branches of pier PA8 during the first train position. The group U1 up to U4 reflects the four strain gauges that are equally divided around the upper part of the branch, while the group L1 up to L4 reflects the four strain gauges on the lower part of the same branch. More precisely U1, U3, L1 and L3 measures longitudinally: U1 and L1 are the strain gauges inside the pier head and U3 and L3 are the strain gauges outside the pier head. U2, U4, L2 and L4 measure in a transverse direction. First of all, it is visible that the strains of the lower part of the branch are significantly higher than those of the upper part. This could be explained because the upper parts of the branches are connected with a top concrete slap and therefore working as a whole. So compared with the lower connection of the branch, the top node is more a rigid one resulting in smaller moments. This was also noticed in the theoretical models. 
Secondly, it is visible that strains in branches 1 up to 3 have an opposite sign with respect to branches 4 up to 6 . This is as expected because the freight train is located on the left of braches 4,5 and 6 , resulting in a rotation of the pier head. In this respect, the strain gauges L1 of branches 4,5 and 6 have a positive sign (tension) and the strain gauges L1 of branches 1, 2 and 3 have a negative sign (compression). The opposite applies for the strain gauges L3. Finally, the strains of strain gauges L2 and L4 are small because of small transversal resultants.

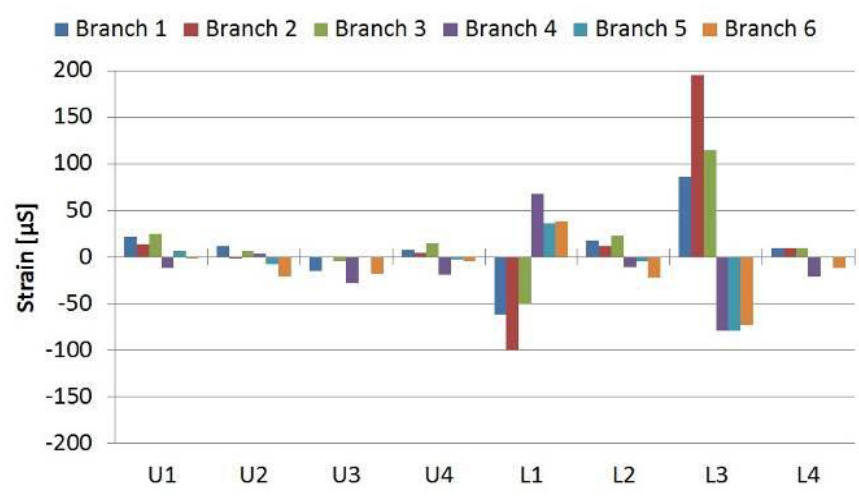

Figure 9: Comparison of the strains in branches 1 up to 6 of pier PA8 while loaded under train position 1 .

Knowing that self-compacting concrete $\mathrm{C} 80 / 95$ is used for constructing the prefabricated branches, young modulus of $\mathrm{E}_{\mathrm{cm}}=42244 \mathrm{MPa}$ could be used for calculating the resulting stresses of the corresponding strains. Figure 10 visualizes some of the maximum stresses measured in the field (red bars) compared to those determined in a theoretical model (green bars). The four left strain gauges originate from pier PA8, while the right strain gauges originate from pier PC10. Also included in Figure 10 are the measured to calculated stress ratios. It can be noticed that the stress ratios are rather small and therefore indicate that the theoretical models are a safe prediction of the reality.

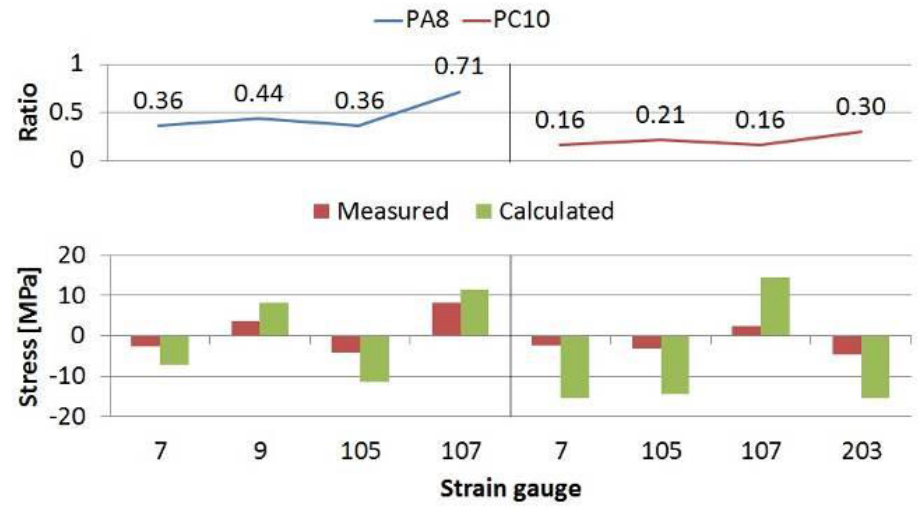

Figure 10: Comparison of the maximum measured stresses in pier PA8 and PC10 with the calculated ones (bottom), stress ratio corresponding with these stresses (top). 
Nevertheless pier PC10 only has to carry one rail track and consists of four branches, the cross-section of the pier itself is the same as the bigger piers like PA8. Therefore, the stress ratios are even smaller here than those of PA8 and it becomes visible that the predictions were too safe concerning the smaller piers, although understandable from an aesthetic point of view.

\subsubsection{Dynamic strain measurements during the load test programme}

After the static measurements, dynamic strain measurements were performed through several braking operations with one or two freight trains. First, the train(s) had to achieve a constant velocity of $60 \mathrm{~km} / \mathrm{h}$ or $80 \mathrm{~km} / \mathrm{h}$ depending on the imposed test. Secondly, several braking operations were carried out at different locations. Therefore, the influence zone of the braking forces in the rail tracks could be measured. This influence zone is a direct indicator of the pier stiffness and the distributing effects of the ballast layer and tracks.

Figures 11 and 12 are a selection of the braking operations carried out with a velocity of $80 \mathrm{~km} / \mathrm{h}$. The location of braking was at pier PA9for Fig. 10 and slightly before pier PC11forFig. 11. For pier PA8, both freight trains were used to brake at the same time. Since pier PC10 only carries one rail track, logically one freight train was used. Knowing that the large freight train covers a length of approximately 3 bridge spans and a velocity of $22,22 \mathrm{~m} / \mathrm{s}$ was used, it takes nearly 1,6 seconds to cross one span length and 4,8 seconds before the whole train leaves the measuring point. This is also visible in Figure 11 where the strain peaks cover the length of 5 seconds. In addition, the peak shift from PA9 to PA8 is 1,6 seconds, which indeed is one span length. In Figure 12, first a compression could be detected because the train had braked just in front of pier PC11. After the compression, a peak of 5 seconds could be detected. Finally many seconds after the peak strains, some strains are still measured while the train is already several spans further. This points the effect of the distribution of the braking forces.

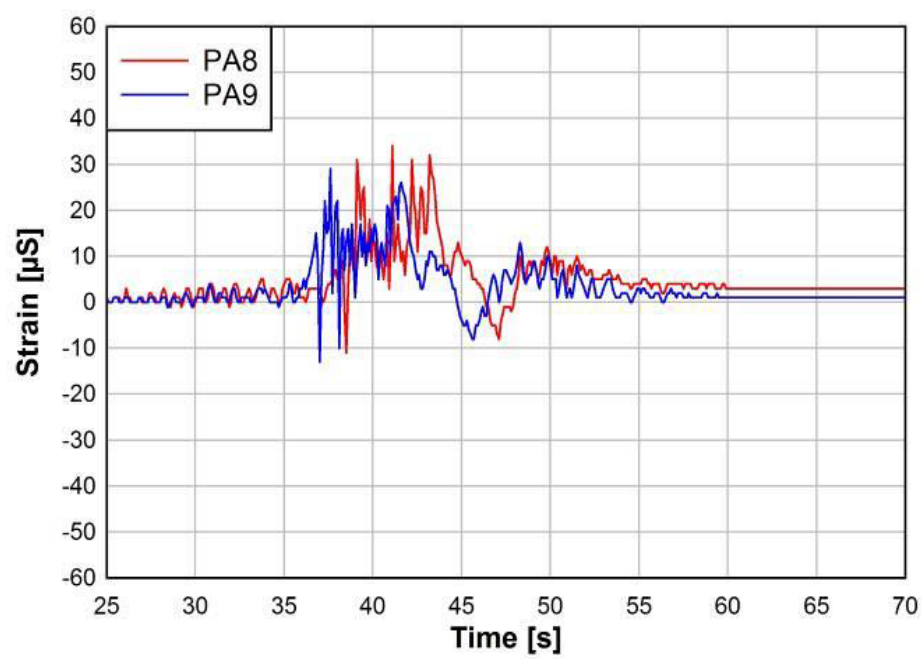

Figure 11: Braking forces in rail track A at pier PA8 and PA9. 


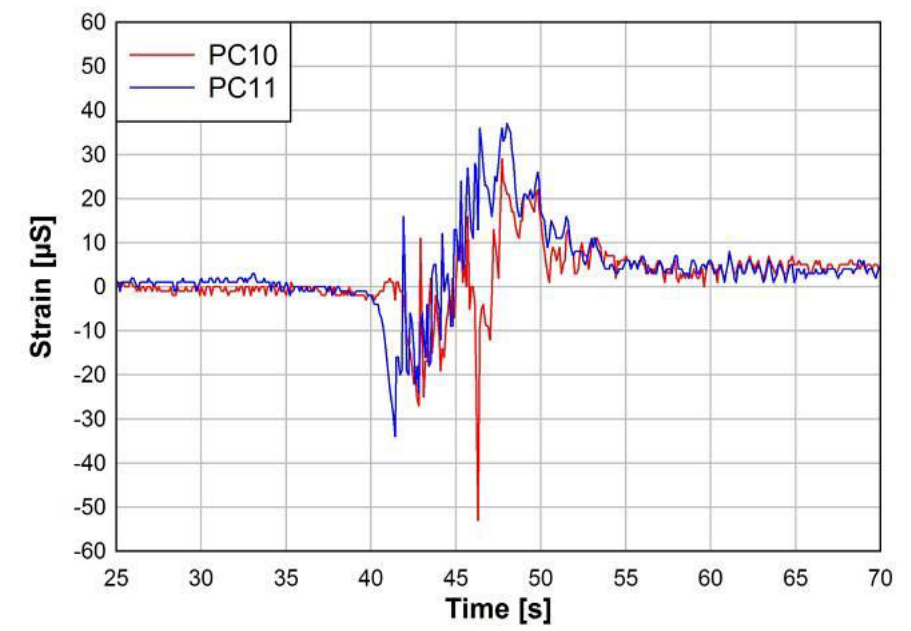

Figure 12: Braking forces in rail track A at pier PC10 and PC11.

During the dynamic strain measurements, the strains of the piers were also measured. These measurements indicated that the strains are significantly smaller than those of the static measurements despite the high braking speeds of $80 \mathrm{~km} / \mathrm{h}$. This signals also a braking distribution over the total length of the bridge and therefore proves the effect of ballast layers. In addition, it indicates that despite the static strain measurements, the use of stiff piers still contribute to a distribution effect.

\subsubsection{Acceleration measurements}

During the previous test, accelerations were measured simultaneously as illustrated in Figure 13. Channels 0 and 1 represent the accelerations on the top of a branch in longitudinal and transversal directions respectively.

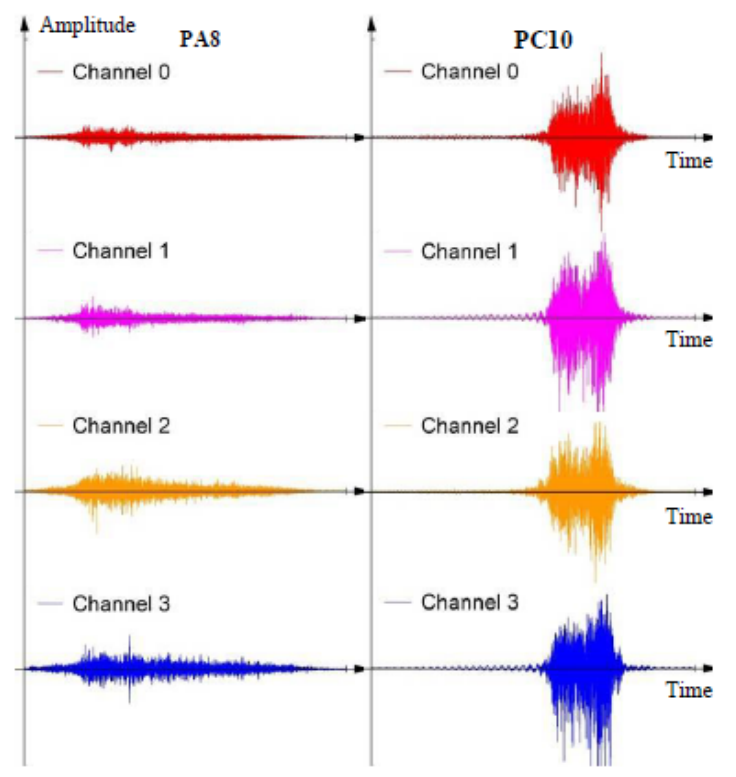

Figure 13: Acceleration measurement in both piers. 
The same goes for channel 2 and 3belonging to the main part of the pier. For every axis, the same scale is used. In this respect, pier PC10 undergoes vibrations with a bigger amplitude than PA8.Nevertheless, also a bigger damping effect is visible for pier PC10 which again reflects the stiffness. It can also be observed that before the train actually reaches pier PC10, a sinusoidal signal imposes itself mainly in the transverse directions. This is because the construction for a single rail track is much more slender than that for a double rail track. It also indicates that the overall Eigen modes of the bridge are determining for the dynamic behaviour. If a frequency analysis is done on these measurements, it seems that the bridge was already vibrating in several eigenfrequencies because of ambient factors. The influence of the trains not really imposes new eigenfrequencies which implies that a forced vibration because of freight trains does not really change the behaviour of the bridge. It was also noted that a wide spectrum of eigenfrequencies existed.

\subsubsection{Long-term measurements}

Apart from the short-term measurements, the long-term behaviour of the structure was also monitored. For that, the strains of pier PA8 and PC10 are monitored for a whole year to investigate the influence of the four seasons. Figure 14 gives an illustration of the daily temperature variations while Figure 15 illustrates the yearly variations. In the latter, a strain gauge on the lower part of a branch and orientated to the south (black curve) is compared with the yearly temperature variations (purple curve). As expected, a similar trend is visible which reflects the influence of temperature on the structure. But for most other strain gauges, no clear correlation exists because of the complexity of the structure. When looking at Figure 14 with the daily variations in the lower part of branch 1 of pier PA8, it becomes clear that not all the strain gauges have the same amplitude as the daily variations resulting in torsional forces. For those where the amplitude is clear, a great similarity is visible when comparing the amplitudes of the daily temperature and the daily strains. It must be remarked that the strain variations in these curves are sometimes $130 \mu \mathrm{S}$ and more. This is much more than the strains detected with the static loading tests. For other strain gauges the influence of the temperature is even more important. In this respect, temperature effects are not negligible especially in combination.

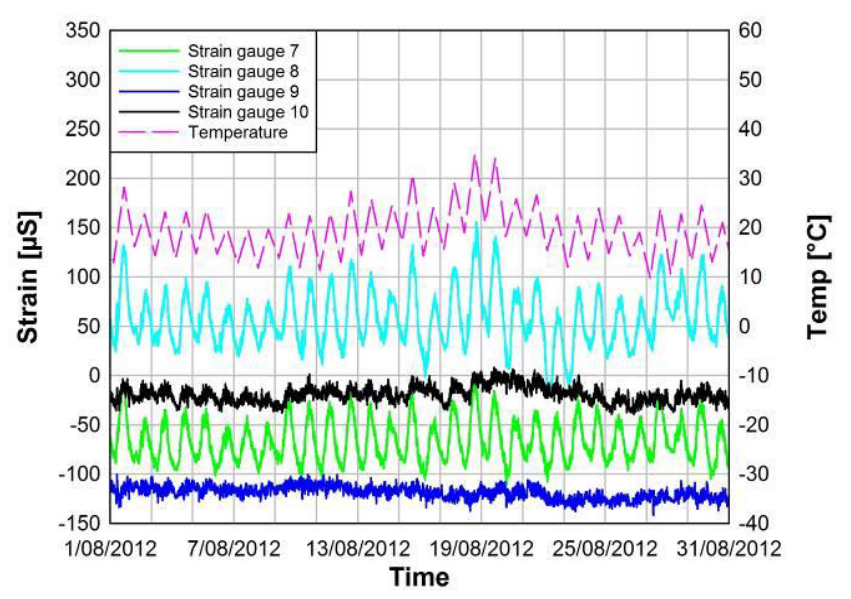

Figure 14: Daily temperature variations and the corresponding strains. 


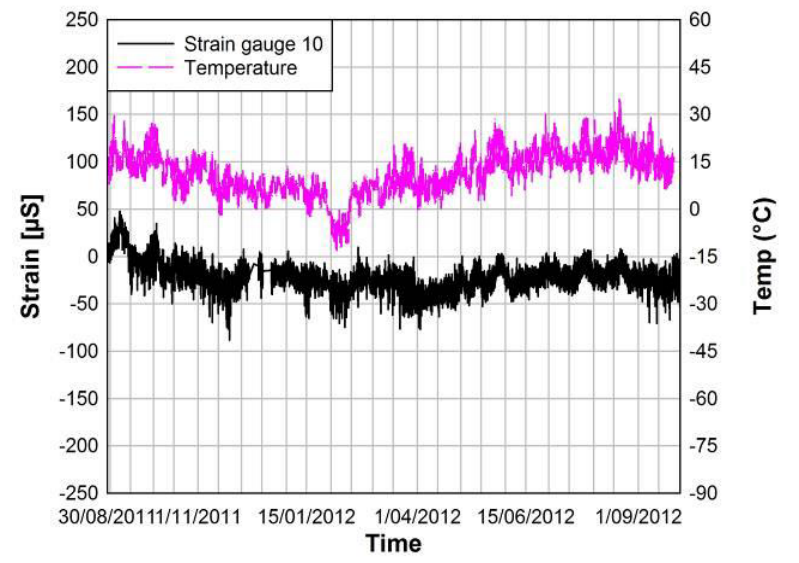

Figure 15: Yearly temperature variations and the corresponding strains.

\section{The Pede viaduct}

\subsection{Design of the integrated steel fly-overs}

After consideration of various alternatives during the pre-design stage, the final design consists of a steel superstructure with variable hollow sections supported by integrated cantilever pier structures, as shown in Figure 16.
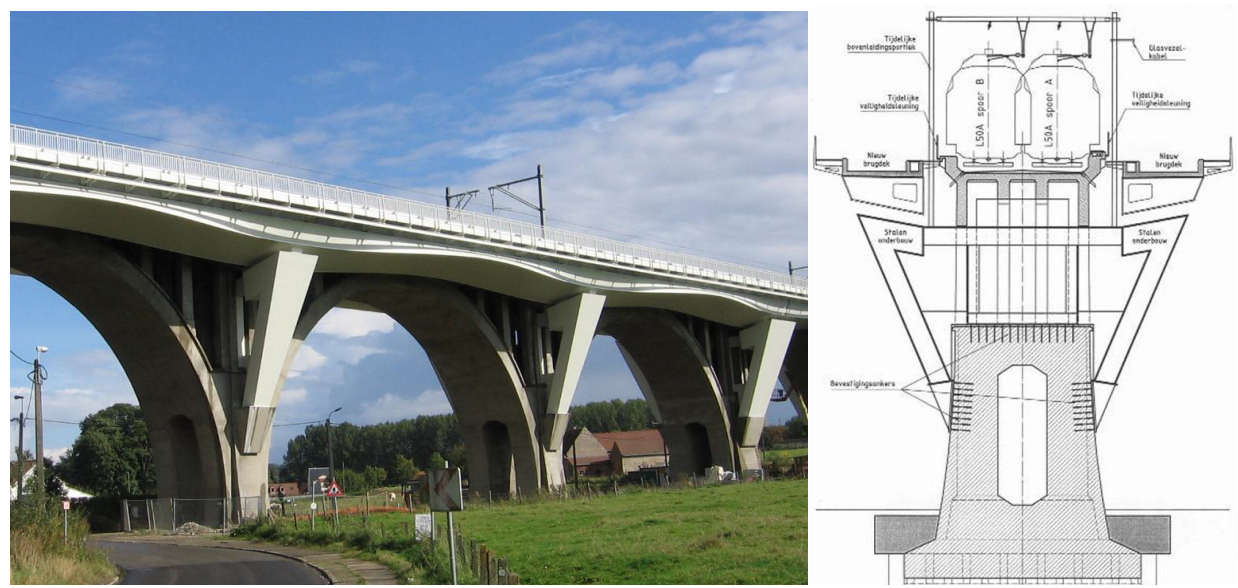

Figure 16: Final design of the integrated steel fly-overs: front view (left) and crosssection (right).

The steel box girders of the superstructure are continuous over 4 spans, in accordance with the existing arches. The box section is characterised by waving patterns, both in plan view as in cross-section. The upper flange of the box section is constant and stays horizontal along the structure's length. The lower flange however has a variable width of minimum $3,65 \mathrm{~m}$ at the piers and maximum $5,15 \mathrm{~m}$ at the span centre. The lower flange rises according to a sine wave from the supports towards the span centre obtaining less height and is twisted about a horizontal axis as it becomes wider. As a result, the vertical box web near the existing concrete arches has variable height, whereas the outer web plate shows torsion along the 
bridge axis. This creates a waving pattern of the steel structure complying with the existing arches, both in horizontal plane as in the front view, as illustrated in Figure 17. To raise the torsion stiffness, internal diaphragms of $20 \mathrm{~mm}$ thickness on a distance of approximately $2 \mathrm{~m}$ each were installed. Additional stiffness is realised by providing a concrete deck plate of $0,25 \mathrm{~m}$ thickness, which allows for spreading the traffic loads and limiting local fatigue problems of the steel structure. The total construction height remains limited in order to guarantee a full front view on the existing viaduct.

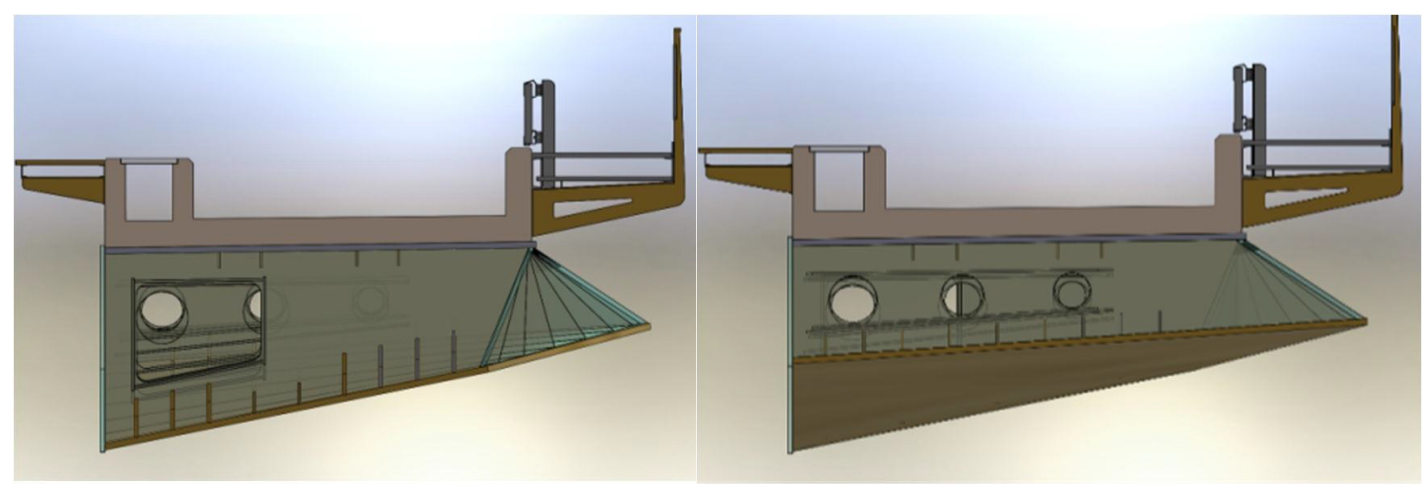

Figure 17: Cross-sections of the steel box at the supports (left) and at mid span (right).

The new superstructure is supported by steel cantilever structures, fixed to the existing piers. Each vertical pier has a rectangular box section in a conical shape and fades into the lower part of the concrete pier. Two cantilever piers are joined by a transverse internal steel framework located in the hollow parts of the existing piers to ensure horizontal stability in transverse direction. As for the horizontal stability in longitudinal direction, the new superstructure is made continuous over 4 spans as mentioned earlier, in order to lead the horizontal traction and braking forces to the double pier structures.

Since the new superstructure is supported by a construction which is fixed to the existing piers, strengthening of the existing foundation was needed due to the additional load. This was realized by grouted piles drilled around the existing footings. The grouting piles are designed to replace the existing concrete piles and are founded at a deeper level to carry the additional load. After drilling of the grouting piles, the existing foundation slab was extended by a new concrete slab and post-tensioning cables were used to put together both the new and existing slab.

\subsection{Measurement program}

\subsubsection{Strain measurements during load test}

In order to verify the design and behaviour of the newly built superstructure, a monitoring program was set up comprising several components. Extensive strain measurements were performed during a two-day load test on the steel fly-overs as well as their supports. At the same time the dynamic response of the structure was 
evaluated by acceleration measurements. Furthermore long term strain monitoring is carried out in order to study the effect of temperature gradients on the closed steel box girders of the fly-overs.

The structure was equipped with a total of 326 strain gauges, of which 216 were attached to the steel superstructure and 110 were installed on the newly built piers and their transverse steel framework. Measurement points were concentrated in several cross-sections of the fly-overs on both flanks of the historic bridge, mostly monitoring strains of the lower flange and vertical web plates in longitudinal direction of the viaduct. However, some strain gauges were used to monitor the diaphragms above the supports or the longitudinal stiffeners of the lower flange. Because of the danger and inconveniences of working on greater heights, all strain gauges of the superstructure were glued to the inside of the steel box, which allowed rather easy access and moving from one compartment to the next through the holes in the diaphragm stiffeners. The strain gauges installed on the pier structures are located on the outside of the conical box sections or on the transverse framework located in the hollow parts of the existing piers. Shielded cables were used for data transfer to the measurement unit in order to protect the strain results from undesirable effects due to adjacent rail traffic.

A total of 12 heavy lorries were applied as loads during the load test, each lorry having a mass of approximately 44 tons. Over the course of two days, the lorries were placed in various positions along the longitudinal bridge axis, in order to investigate the effect on different structural members. As an example, the full loading condition of a 4-span deck is shown in Figure 18. Lorries could be placed on both sides of the bridge, for example to obtain maximum loading of the local pier structure, or only on one side, for instance to investigate the asymmetric loading of the internal pier framework. During the test, strains were recorded with an accuracy of 1 microstrain $(\mu \mathrm{S})$ as has been proven on many other cases. Prior to every monitored sequence of consecutive lorry configurations, a zero measurement of the unloaded viaduct was registered in order to discard the measurement results from daily thermal effects.

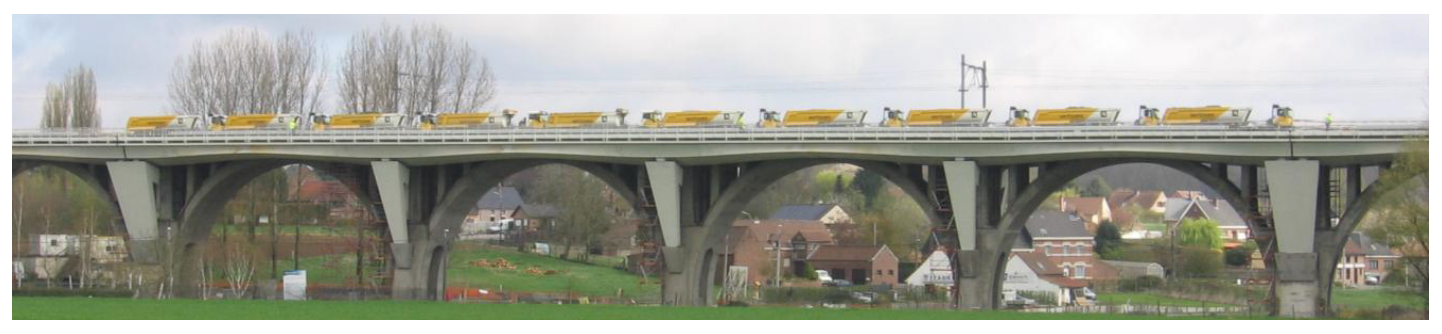

Figure 18: Load test of a continuous 4-span deck using heavy lorries.

In addition to the static load cases, dynamic strain measurements were carried out during the two-day testing program. These included brake tests of five lorries stopping at the same time as well as continuous monitoring of the longitudinal stiffeners on the lower flange during passage of a 10-lorry convoy at low speed. 


\subsubsection{Long-term measurements}

In the period after the load test, long term monitoring of a selected number of strain gauges was initialised. Therefore a fully autonomous measurement system was installed, consisting of a data logging set-up powered by 4 lithium-ion D-cell batteries to assure the independency of the system and the continuation of the monitoring in case of power failure on the construction site. Strains are monitored continuously in 15 well-chosen points of the superstructure, mainly to study the effect of temperature gradients on the closed steel box girders of the fly-overs. For this reason, temperatures are being measured on 8 locations of the steel structure. As the superstructure is made continuous over 4 spans, temperature effects are also monitored on 14 points of the steel supports integrated in the hollow concrete piers. A Wheatstone half-bridge configuration was applied for every measurement point thanks to the use of two orthogonal measuring grids on each strain gauge. This should result in more stable long-term measurements due to a nearly complete elimination of unwanted temperature effects and influences of the leadwires on the resistance.

\subsection{Results}

\subsubsection{Strain measurements during load test}

A selection of the large amount of measurement results is presented to demonstrate the accuracy of the measurement set-up and to illustrate the usefulness in verifying design assumptions. By convention, tensile stresses correspond to positive strains, compressive stresses to negative values.

As part of the two-day load test, strains were measured in corresponding sections of deck 7 and 8. Both are continuous 4-span decks, but located on opposite sides of the historic arch bridge at the same position along the longitudinal axis. Figure 19 shows the comparison of strain results from deck 7 and 8 in 35 measurement points for three consecutive lorry configurations. In each of these configurations, the positioning of the lorries was identical for deck 7 and deck 8. Each line in Figure 19 corresponds with the strain variation of a single measurement point over the three load states. As the graph shows, strain results from deck 7 correspond well to strains measured in deck 8 and their variation over the sequence of lorry configurations shows the same tendency for every measurement location. As the absolute values of the measured strains are quite small, some caution is advised in performing extensive statistical analysis on the monitored data. Nonetheless, an average difference of $3 \mu \mathrm{S}$ between results of deck 7 and 8 can be noted, with a standard deviation of $3 \mu \mathrm{S}$, which demonstrates the good agreement between the corresponding measurement sections. 


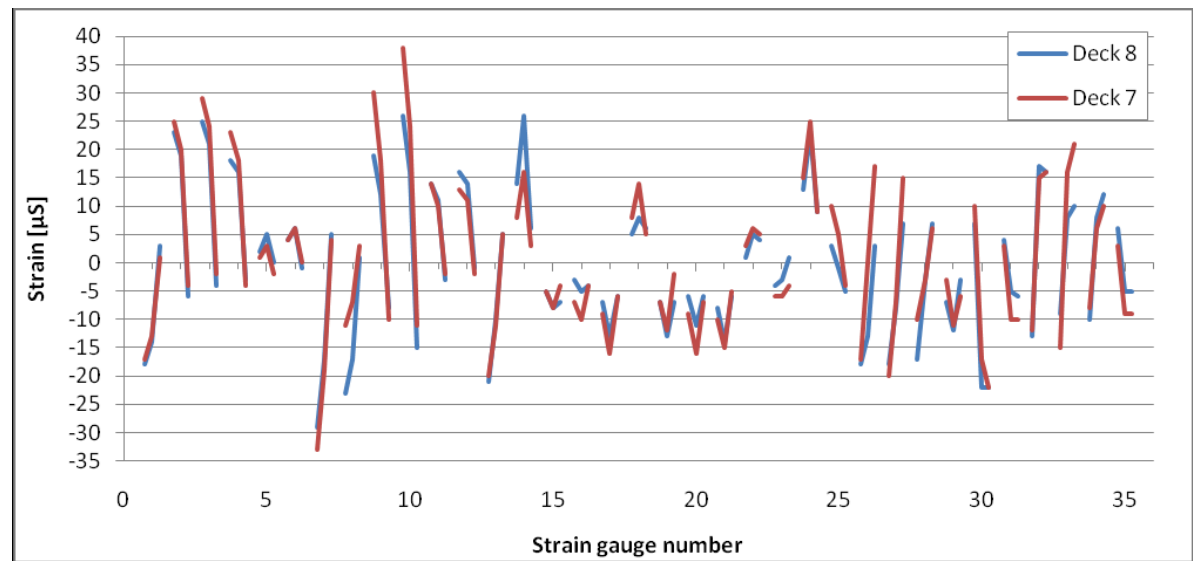

Figure 18: Comparison of strain variations of deck 7 and 8 over three consecutive lorry configurations.

Figure 19 shows strain results of deck 6, where only the first span (D) was loaded and no lorries were positioned on the other spans (A,B,C). Strain gauges 1 and 7 are located at the top of the box section, while the other gauges are located at the bottom, as shown in Figure 20. Loading of span D results in compressive stresses at the top of the cross-section at mid span and tensile stresses at the bottom.

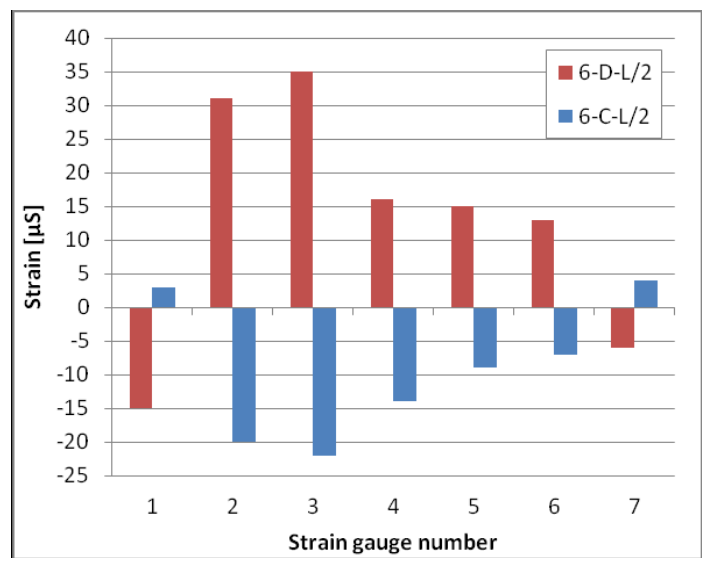

Figure 19: Strain results of deck 6 (only span D loaded).

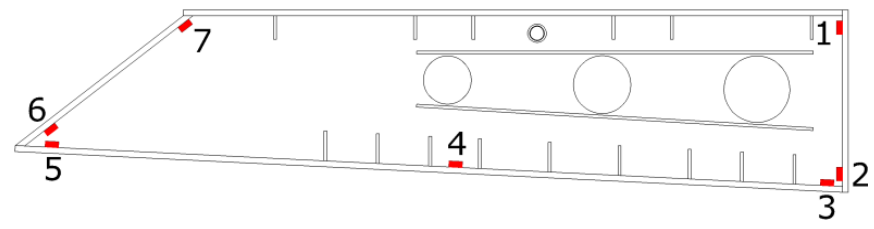

Figure 20: Location of strain gauges in deck 6.

Simultaneously, the upward response of the adjacent and unloaded span C (due to the deck being continuous over four spans) results in tensile stresses at the top and compressive stresses at the bottom of the cross-section at mid span. Figure 21 shows 
strain results of the same cross-sections in span C and D of deck 6 , this time under simultaneous loading of both spans. This condition was found in two different lorry configurations, being positions 3 and 13, which allows for a comparison of monitored strains in both positions. The results depicted in Figure 21 show a good resemblance between positions 3 and 13 in both cross-sections of deck 6 . In general, the strains in span $\mathrm{C}$ remain smaller as in span $\mathrm{D}$, which corresponds to the smaller bending moment in span $\mathrm{C}$ under the applied loading condition.

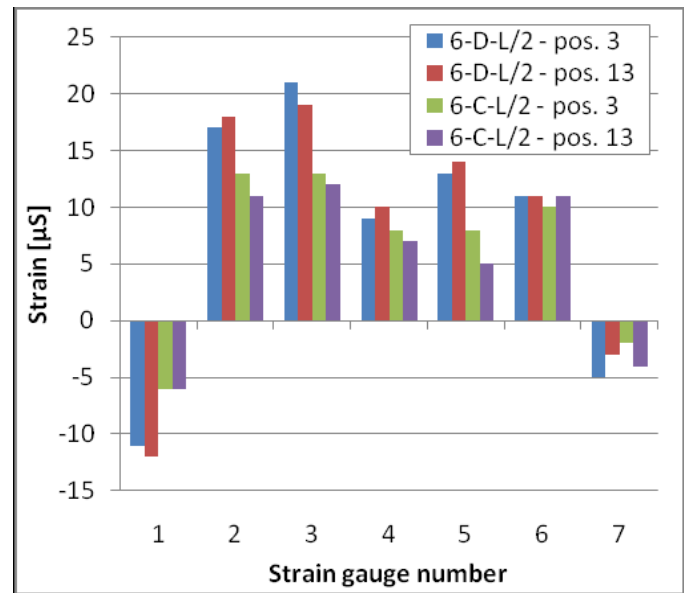

Figure 21: Strain results of deck 6 (spans C and D loaded).

During the load test, the maximum loading condition of the piers was simulated by positioning lorries on both sides of the pier in longitudinal direction and at the same time on both decks of the fly-over in transverse direction. As the cantilever piers of a double pier structure are joined by two separate transverse internal frameworks, strain data from corresponding locations on both frameworks can be compared. Therefore, results of this loading case for the double pier structure of pier 13 are shown in Figure 22. In spite of the small absolute values of the measured strains, a good resemblance of the results for both frames can be observed.

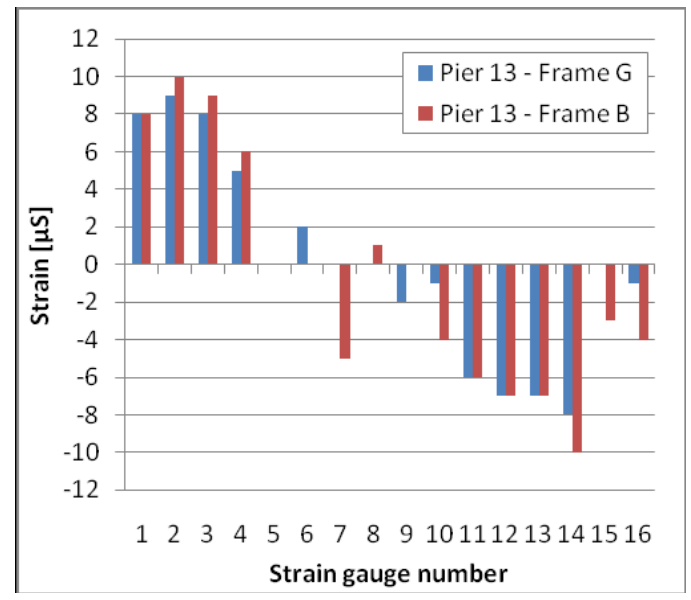

Figure 21: Strain results of both frames of pier 13 (maximum loading condition). 


\subsubsection{Long-term measurements}

Long term monitoring of the steel box section of the fly-overs allows for evaluating the effect of temperature gradients on the superstructure. Figure 22 gives an illustration of the daily temperature variations during the summer in several crosssections of deck 8 , which is oriented to the southwest. The graph shows that the temperature of the inner web plate near the existing concrete arches ('in') is almost identical along the entire length of span D of deck 8, and shows rather small variations between day and night temperatures. On the other hand, temperatures on the outer web plate ('out') become much higher during daytime and cause a temperature gradient in the steel box section. In addition, the outer web plate at mid span shows significant higher temperatures than the cross-sections at L/4 and the supports, due to a larger exposure to solar radiation on the inclined steel surface. As a result, the largest temperature gradient between inner and outer web plate occurs at mid span and reaches almost $15^{\circ} \mathrm{C}$, while this difference is only $6^{\circ} \mathrm{C}$ at the supports.

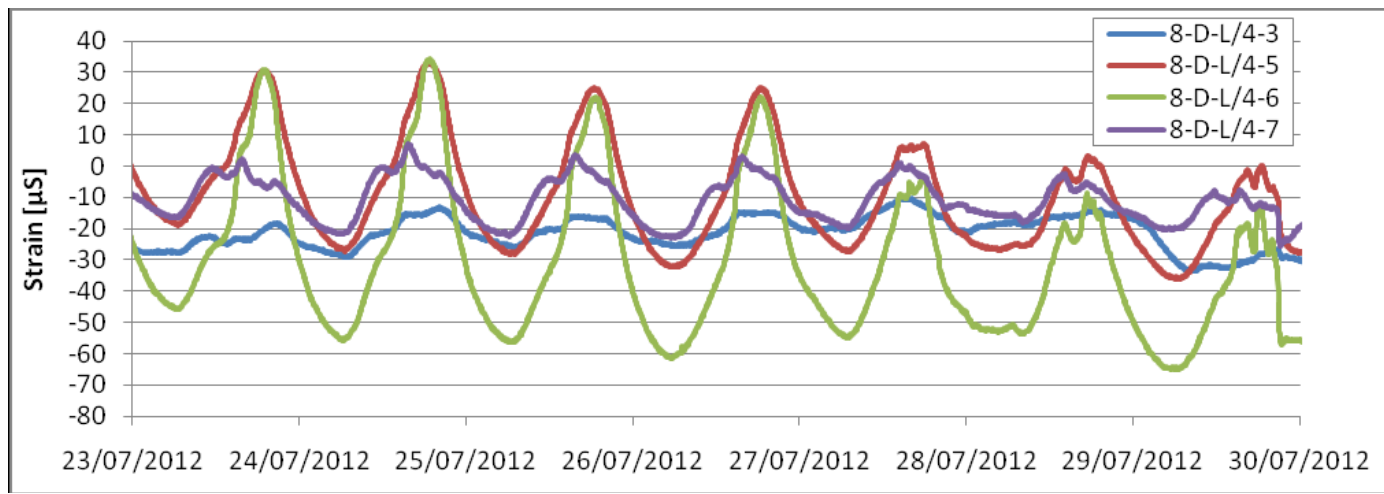

Figure 22: Strain variations in steel superstructure due to temperature variations during summer.

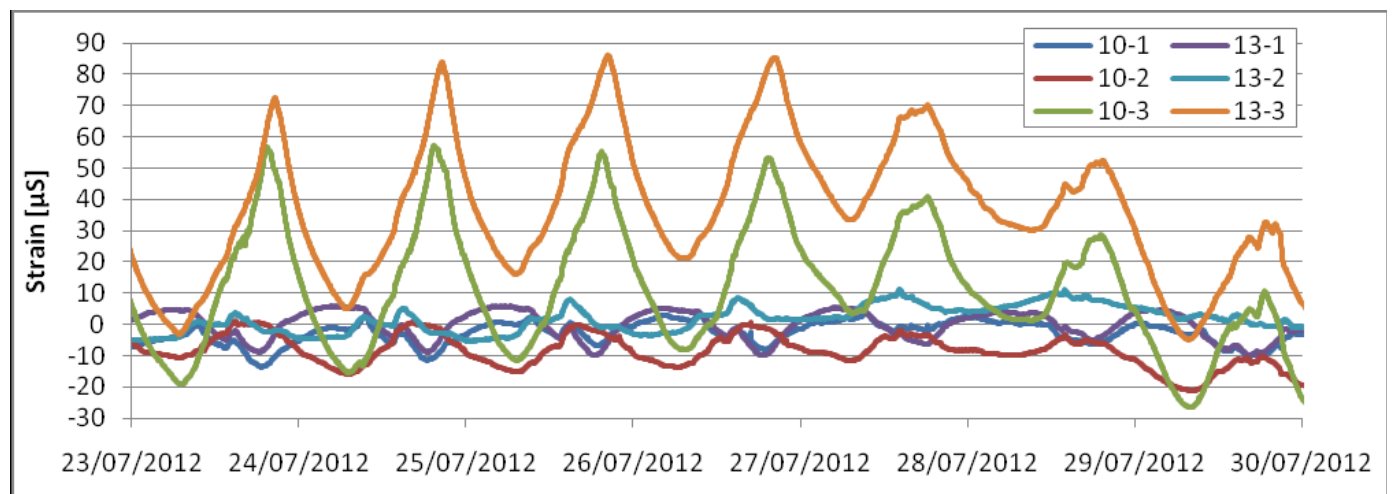

Figure 22: Strain variations in pier structures due to temperature variations during summer.

As an example, Figure 22 shows the impact of the temperature variations on monitored transverse strains in the cross-section at L/4. The numbering of the strain 
gauges is similar to Figure 20. When temperatures rise during daytime, an increase of tensile stresses can be observed due to the thermal expansion of the steel superstructure. The largest strain variations occur in gauge numbers 5 and 6 , which are located at the lower outer corner of the steel box section. The temperature effects on the superstructure can also be observed in the monitoring results of the pier structures, as illustrated in Figure 23. Corresponding measurement locations in piers 10 and 13 give a comparable response to the thermal effects, with maximal tensile stresses generated in strain gauge number 3, located on the lower connection plate between the conical box section of the piers and the internal framework.

\section{Conclusions}

In order to verify the structural assessment and the durability of a civil structure, a monitoring programme imposes itself. Depending on the structural parameters to be investigated a short-or long-term testing programme is needed. As for the short-term behaviour of a structure, a lot of data could be achieved using strain gauges and accelerometers. In the case of the Iris railway viaduct, it becomes clear that the testing programme worked properly, resulting in a better understanding of the complex structure. As often the case for design rules, calculations are rather conservative and therefore result in a safe prediction. This was also noticed when comparing the measured strains with the theoretical ones. When looking at the longterm behaviour of a structure, both temperature changes and strains are important values to register. It seems as if the daily variations of the temperature have an important influence on the structure, even more so than the strain variations measured during static load tests. A possible conclusion could be that daily temperature variations cannot be neglected in the design although often regarded as a minor load. Although this paper reflects the structural assessment of one bridge in particularly, these techniques are applicable for several other.

This paper showed a selection of the results of the extensive monitoring program verifying the structural behaviour of the newly built lateral fly-overs in expansion of the historic multiple-arch viaduct crossing the Pede valley. During a two-day load test and following long term measurements, detailed strains, temperatures and frequencies were monitored which allow for evaluating the conceptual design. The accuracy and reliability of the results were illustrated in various examples of the structural response. The performed measurements provide the designers the ability to assess the behaviour and stiffness of the structure under static, dynamic and thermal loading cases.

\section{References}

[1] P. Van Bogaert, B. De Pauw, "Modelling and building of the piers of the Iris railway viaduct", in "Proceedings of the FIB Symposium, Prague 2011", Prague, Czech Republic, 1-10, 2011. 
[2] H. De Backer, A. Outtier, K. Schotte, D. Stael, W. Nagy, P. Van Bogaert, "Experiences with SHM for large civil structures", in "Proceedings of the 5th International conference on Structural Health Monitoring of Intelligent Infrastructures", Cancun, Mexico, 1-10, 2011.

[3] P. Van Bogaert, B. De Pauw, "Integrated steel viaducts for railway in extension of a historic multiple-arch concrete viaduct", in "Proceedings of $8^{\text {th }}$ International Conference on Short and Medium Span Bridges", Niagara Falls, Canada, 198.1-198.10, 2010. 